\title{
LA VOZ POÉTICA DESDE EL CANTAR Y EL ROMANCERO HASTA MIO CID CAMPEADOR, HAZAÑA DE VICENTE HUIDOBRO
}

\author{
Benjamín Franzani \\ Universidad de los Andes \\ Santiago, Chile \\ bfranzani@uandes.cl
}

Vicente Huidobro publica su Mio Cid Campeador, Hazaña en 1929. Esta, que es su primera novela, "representa perfectamente un periodo de ímpetu creacionista" (Saldes 1), que podría enmarcarse, según la periodización que hace Cedomil Goic de la evolución de la teoría poética de Huidobro, dentro del segundo momento de la toma de conciencia de la poesía, es decir, el de la "esencia del estado poético" (87). Este estado poético, en el que el artista concibe el poema, es para Huidobro un momento de "delirio poético" al que llama "supraconsciente", porque en él se agudizarían las facultades intelectuales del artista, guiado por la inspiración y una razón ordenadora, que le permite concebir el poema y dar paso a la creación de un mundo nuevo (Goic 88-89).

Es dentro de este movimiento que se enmarca la obra que estudiamos: Huidobro es plenamente consciente de su poesía y, lo que es más importante para el caso que nos ocupa, es consciente de estar creando a través de la palabra, dando vida a un mito. Sin embargo, la creación del poeta es una creación de segundo orden, pues no crea desde la nada, sino desde lo ya preexistente (Goic 66-67). De ahí la conocida afirmación de su Arte poética: "el Poeta es un pequeño Dios" (Huidobro, Antología 17). En el caso de Hazaña, Huidobro ha trabajado para dar vida a su poema la vasta tradición cidiana: en efecto, la obra denota un amplio conocimiento sobre la leyenda y la historia del Cid, y no solo del Cantar, sino también del Romancero. Así lo hace constar él mismo: "en los datos sobre el Cid, a veces he seguido al Cantar, al Romancero y a la Gesta, y otras veces he seguido la historia" (Mio Cid 17). 
Huidobro nos narra la vida de "su" Cid, pero la obra no es una simple recepción de una historia conocida y ajena. Ni siquiera es una simple "reescrituración" del mito, o una actualización. Se trata, afirma el autor, de una novela fundacional de un género (Saldes 1), la novela de poeta: “'la Hazaña' es la novela de un poeta y no la novela de un novelista. Hay muchos poetas que hacen novelas de novelistas. Allá ellos. Yo no participo de ese vicio. Solo me interesa la Poesía y solo creo en la verdad del Poeta" (Mio Cid 17).

Esta particular conciencia de lo que hace, de estar con sus palabras construyendo una verdad, acerca a Huidobro a la actitud de los antiguos juglares. En su estudio sobre el Cantar de Mio Cid, Montaner nos hace ver que, a propósito de algunos pasajes enteramente inventados, el autor

se atuvo de forma consistente a la vieja apreciación aristotélica de que "el historiador y el poeta no se diferencian por decir las cosas en verso o en prosa..., la diferencia está en que uno dice lo que ha sucedido y el otro lo que podría suceder" (Poética 51b 1-5), o en términos que a él le resultarían más cercanos, a la advertencia de San Jerónimo: "Quia carmen est... historiae ordo non quaeritur" ("El Cantar" 271).

Huidobro, pues, recibe y se apropia de la tradición cidiana, apropiación que realiza entrando en diálogo con los textos, según veremos, para a partir de allí dar vida a su propio Cid, a la medida de su teoría creacionista.

\section{MIO CID CAMPEADOR, HAZAÑA Y LA TRADICIÓN DEL ROMANCERO Y DEL CANTAR. EL MARCO DE REFERENCIA}

La evidente relación entre la novela de Huidobro y la tradición cidiana lleva a plantear la necesidad de la comparación entre estas. La recepción y apropiación de las obras antiguas están acreditadas por el mismo Huidobro, quien no solo declara sus fuentes sino que transparenta que se ha tomado libertades para adaptarlas a su gusto: "en varias ocasiones he corregido la historia con el derecho que me da la voz de la sangre, y aun he agregado algunos episodios desconocidos de todos los eruditos y que he encontrado en viejos papeles de mis antepasados" (Mio Cid 18).

Hazaña está en evidente diálogo con la tradición, un diálogo que Huidobro hace tan concreto que no solo reproduce textualmente algunos giros que el lector familiarizado con la leyenda reconocerá enseguida-como la exclamación 
"Dios, qué buen vasallo, si tuviese buen señor" o los epítetos que tanto el Romancero, como el Cantar y Huidobro dan al Cid: "el que en buen hora ciñó espada" y "el que en buen hora nació" - sino que llega a hacer del Cantar una realidad concreta dentro de su novela: "entonces, en el momento en que [el Cid] va a pasar el umbral, una chica de nueve años se desprende del Cantar y acercándose al Campeador le habla con ingenuo y sabroso ritmo de verso" (Huidobro, Mio Cid 242). Y más aún: Romancero y Cantar llegarán a ser personajes de la novela (como también lo son, otro tanto, el mismo autor y el lector): "detrás de la puerta [del destierro] los espera el Poema con los brazos abiertos. El Cantar se cuelga al cuello del Cid y le besa a boca llena (.-) El Romancero le regala una magnífica espada: Tizona" (Huidobro, Mio Cid 258); "La Historia, la Crónica, la Leyenda el Poema, le lanzan paquetes de laureles" (Huidobro, Mio Cid 345).

Para comparar la antigua materia de la leyenda con la nueva elaboración de Huidobro, es necesario establecer en primer lugar un marco de referencia (Nivelle 203), que nos permita trabajar los textos sin forzarlos: es decir, es necesario poner en referencia la obra literaria con la cultura en la que se inserta.

La comparación de nuestras obras se ve dificultada, pese a lo cercanos que parecieran los textos en virtud al tema, por la distancia temporal y cultural. En efecto, el ámbito de producción del Cantar y del Romancero corresponde a lo que Walter Ong denomina una "cultura oral primaria" (11), mientras que la obra de Huidobro pertenece a nuestras modernas culturas caligráficas: la diferencia implica un modo totalmente distinto de pensar y de concebir el mundo, y por lo tanto también de comunicarse.

Mientras que para una cultura oral las palabras son hechos, sucesos, acontecimientos fugaces e intangibles como el sonido mismo (que no se puede retener) -y por lo tanto radicalmente ligadas al poder y a la magia-, para las culturas caligráficas como la nuestra las palabras son concebidas como cosas, cosas que se ven, escritas "fuera", sobre una superficie plana (Ong 39$)^{1}$. Es por ello que, para el juglar y sus oyentes, la recitación implicaba una acción evocadora, un hacer presentes los acontecimientos narrados, implicando íntimamente a los que oían. No operaba el automático distanciamiento que interpone la palabra escrita entre el lector y lo narrado:

Para las características distintivas de las culturas orales y sus diferencias con las culturas en las que se ha difundido ampliamente la escritura, véase Ong, "Algunas psicodinámicas de la oralidad" (38-80). 
Una canción de gesta pone a un juglar frente a un público, sin apenas distancias, sin mediaciones, para recorrer juntos durante varias horas los derroteros de una narración heroica. El juglar no es como el escritor que publica una novela y se esfuma para siempre tras el volumen impreso: está en medio del corro, el desarrollo de la narración es también una acción suya, un comportamiento suyo personal, que además tiene que ver con la relación que tiene con los oyentes (Rico 222).

Tomando en cuenta la separación cultural que distancia a la tradición cidiana del Cid Campeador de Huidobro, no podemos decir sin más que el marco de referencia sobre el que basar nuestra comparación sea la cultura común. Hemos de encontrar otro punto de contacto. La respuesta más inmediata es la materia de las obras: las hazañas de Rodrigo Díaz de Vivar y las muchas intertextualidades que se pueden apreciar entre ellas. Sin embargo, aun siendo esto cierto, no nos parece lo esencial: el mismo Huidobro no duda en afirmar que su novela es "un pretexto para acumular poesía" (Mio Cid 17): su intención principal es esa, hacer poesía, y secundariamente cantar las hazañas del héroe, precisamente al contrario de lo que hacían los autores antiguos, cuya primera intención es la de cantar una gesta, siendo el verso, aun cuando estuviese muy finamente trabajado -como ocurre en obras como el Cantar de Mio Cid o la Chanson de Roland-más bien un recurso mnemotécnico, que permitía las largas recitaciones de memoria para las que estaban pensadas los cantares (cfr. Ong, 40-42; Montaner, "El Cantar" 302-304).

Hay sin embargo algo en lo que coinciden Cantar y Romancero, por un lado, y Huidobro, por el otro: la manera de narrarnos la historia del Cid. En todos ellos, la posición del poeta en la historia es activa e interpela al auditorio/al lector a involucrarse también en la historia. Todos pretenden hacer presente una ficción como si esta realmente tomase cuerpo al ser oída/leída. Es la verdad poética, que Huidobro proclama preeminente para el arte (Mio Cid 17). Más arriba ya apuntábamos cómo en las culturas orales la recitación involucra a juglar y público. Ong afirma que orador y auditorio forman una unidad, cosa que no ocurre con los lectores de una novela (77-78). Montaner, por su parte, recuerda que el poeta

debía satisfacer un presente (el de su auditorio) con un relato donde el pasado era un punto de referencia y una fuente de inspiración, pero en el que lo verdaderamente importante eran las aventuras del héroe. El poema épico no pretendía dar lecciones de historia (aunque sus 
episodios podían ser escuchados como tales, según sabemos), sino impresionar y emocionar a su público, y eso pasaba inevitablemente por hacer presente a su héroe ante el auditorio ("Presentación" X-XI).

Y, precisamente, esta es la misma actitud que encontramos en Huidobro, que escribe encarnando sus postulados creacionistas. Porque el creacionismo consiste precisamente en eso: hacer presente, crear, el relato, la verdad poética, e implicar de ese modo a su público. Recordemos aquí algunos de los versos de su "Arte poética":

Cuanto miren los ojos creado sea, Y el alma del oyente quede temblando

Inventa mundos nuevos y cuida tu palabra;

El adjetivo, cuando no da vida, mata.

$$
[\ldots]
$$

Por qué cantáis la rosa, ¡Oh Poetas!

Hacedla florecer en el poema. (Antología 17).

El creacionismo postulado por Huidobro le lleva a posiciones similares a las de la cultura oral en la que se generaron el Romancero y el Cantar, en lo que a relación con sus receptores se refiere: la voz poética de su novela pretende involucrar a sus lectores, sumergirlos en la acción del relato; entrando en él, da vida a sus personajes, que parecieran actuar frente a nosotros, pues de hecho dialogan con el poeta -así ocurre en el pasaje en que la sombra del Cid cuestiona la descripción que Huidobro hizo de Jimena (Mio Cid 60-61)o el poeta mismo interviene en la historia -“en un segundo sus caballeros le rodean para protegerle, y yo convierto mi pluma en lanza y atravieso diez moros" (Mio Cid 297)-. Sirva, sin embargo, por todos, el ejemplo del siguiente pasaje:

Lector, para seguirle en esta etapa vertiginosa, debemos coger un anteojo de larga vista y largos siglos y enfocarlo en el año 1081. Veamos. Pon tus ojos en él y enfoca. ¿Qué estás mirando? [...]-Veo al Cid Campeador, al que en buen hora nació y en mejor hora ciñó espada, al de la noble barba crecida... (254).

El lector es así un participante activo de la novela de Huidobro, la ficción por él urdida le hace entrar en ella como un personaje más, como si estuviésemos 
en medio de una representación. Es esta actitud activa e integradora por parte de la voz poética la que resulta de mayor interés de estudio, pues es la que en definitiva permite conectar a Vicente Huidobro con la tradición de los anónimos juglares.

\section{EL HECHO COMPARATISTA}

El marco de referencia ha quedado constituido por la materia de la que tratan las obras (las hazañas del Cid) y por la posición que adopta el poeta para narrar la historia. Esto último, a lo que podemos llamar la posición enunciativa de la voz poética, constituye lo que Brunel llama el hecho comparatista (21). Hay, sin embargo, que precisar aquí que el concepto es aplicado por Brunel a la aparición de elementos extranjeros en una obra, que permiten compararla con otras obras de cuyas literaturas proceden esos elementos. Aunque en la novela de Huidobro encontramos algunos -como galicismos o anglicismos deliberadamente sueltos entre las páginas de la novela-estos son totalmente ajenos al Cantar y al Romancero, y, por ende, no permiten establecer una relación con esos textos -aunque sí permitirían estudiar su relación con otros de esas lenguas-. Sin embargo, la novela acoge otros elementos que podríamos, por extensión, considerar como "extranjeros" desde el momento en que migran desde la cultura oral en que nacieron para entrar en la obra de Huidobro y la nueva vida que les da el creacionismo. Este elemento es precisamente la posición enunciativa de la voz poética de la que ya hemos hablado y que nos permite establecer la relación con la obra de Huidobro. No nos parece forzada esta extensión, toda vez que el mismo Brunel no duda en calificar analógicamente como "extranjeros" los elementos mitológicos que se pueden encontrar en la literatura más reciente, provenientes de la antigüedad grecolatina (24).

Huidobro recibe esta voz y toma la posición de esta en la novela, es decir, la hace propia, ocupa el lugar del juglar. Pero, al mismo tiempo, la transforma: para usar los términos de Subercaseaux, la suya no es una mera recepción, sino una "apropiación". Huidobro nos habla desde su calidad de "nieto" del Cid y, por lo tanto, es la voz mejor autorizada para contar sus hazañas (Mio Cid 18).

Siguiendo a Brunel (21), quien postula tres leyes para el estudio del hecho comparatístico -la ley de emersión, de flexibilidad y de irradiación-, diremos que la voz poética de las culturas orales "emerge" en el texto de Huidobro, a la vez que "irradia" su influencia a toda la obra. La flexibilidad, en cambio, 
no es tan clara aunque está ahí: Huidobro maneja la voz poética de la que se ha apropiado de modo que, a veces, actualiza su sentido y en otras conserva su sabor arcaico, según el efecto que desee conseguir.

¿Cómo identificamos esta voz? En el texto se manifiesta, principalmente, a través de la repetición de aquellos mecanismos que en la cultura oral permitían al recitador llamar la atención directamente de su público, y que Huidobro utiliza en su novela precisamente para crear esa sensación de inmediatez propia de su obra. En otras palabras, se hace evidente cuando podemos entrever la presencia del narrador en el texto, hablándonos directamente a nosotros.

La voz poética del Romancero y del Cantar aparece numerosas veces en la novela, ya sea a través de citas textuales o de parafraseos y alusiones. Especialmente notables son las veces en que Huidobro toma manifiestamente la posición que correspondería a un juglar que habla a su público, creando la ficción para el que lee de estar presente a la recitación. Así ocurre cuando hace suyos los numerosos "odredes lo que á dicho" (Cantar v. 70) para afirmar también él: "vais a oír lo que les dijo" (Huidobro, Mio Cid 39).

Otras veces, no aparece explícitamente esta presencia, pero la reconocemos al intercalar Huidobro versos del Cantar o del Romancero, no sin antes modificarlos para adecuarlos al tono que quiere dar a su relato, donde podemos vislumbrar la ley de flexibilidad. Así, por ejemplo, al hacer hablar a la niña que sale al paso del Cid en Burgos. Dice el Cantar:

$\begin{array}{ll}\text {-iYa Campeador, } & \text { en buen hora cinxiestes espada! } \\ \text { El rey lo ha vedado, } & \text { anoch d'él entró su carta } \\ \text { Con gran recabdo } & \text { e fuertemientre sellada. } \\ \text { Non vos osariemos } & \text { abrir nin coger por nada; } \\ \text { Si non, perderiemos } & \text { los averes e las casas, } \\ \text { E demás } & \text { los ojos de las caras. } \\ \text { Cid, en nuestro mal } & \text { vós non ganades nada, } \\ \text { Mas el Criador vos vala } & \text { con todas sus vertudes santas. } \\ \text { (vv. 41-48). }\end{array}$

Y Huidobro:

-Campeador, que en buen hora ceñiste espada, no podemos, Mio Cid, darte asilo por nada; el rey nos lo ha prohibido con severas amenazas. Si te abrimos perderemos los haberes y las casas, perderemos nuestros ojos, nuestros cuerpos y aun las almas. No podemos albergarte, ni 
tampoco venderte nada, ni trigo ni pan, ni viandas, ni la ración más menguada. Cid, en el mal de nosotros vos no ganaréis nada. Seguid y que Dios os proteja y la tierra os sea ancha (Mio Cid 242).

Como se ve, Cantar y Romancero funcionan de hipotexto de la Hazaña. Esta constituye una relación de hipertextualidad (Genette 57), en la que se modifica la fuente según las intenciones del poeta: nótese cómo, aunque modernizó el lenguaje, el pasaje no pierde su ritmo poético y, además, la amenaza que pesa sobre los burgaleses resulta magnificada: no ya los ojos, sino las almas mismas las arriesgan de albergar al Cid.

Otro tanto ocurre con la construcción "rey don Sancho, rey don Sancho" con la que el Romancero comienza el relato de la muerte de este rey, en el que pareciera que el poeta quiere advertir del peligro al señor de Castilla (Romancero 37). Huidobro hace propio el giro y utiliza la fórmula en el ingenioso pasaje en que el Hada Madrina de España, por un lado, y la Envidia, por otro, susurran alternativamente al oído de don Alfonso: "Rey Alfonso, rey Alfonso [...] el Cid es el hombre que te conviene". "Rey Alfonso, rey Alfonso, el Cid se cree más que tú" (Mio Cid 218-219).

Los giros de este estilo son incontables, así como las citas textuales del Romancero y del Cantar. Bien podemos decir que la novela de Huidobro es un entramado de intertextualidades, que la voz del juglar emerge una y otra vez, pero, al mismo tiempo, es algo distinto, pues la historia se va desarrollando según el propio interés de Huidobro, eligiendo unos pasajes y no otros, ampliando algunos, inventando otros más. Así, por ejemplo, Huidobro exalta la lealtad del Cid hacia su señor, tal y como hace el Cantar, pero esta no llega a ser tan incondicional que no llegue nunca a oponerse al rey. Por su parte, el Alfonso de Huidobro nunca llega a amar a su vasallo como lo hace el rey del Cantar y, de hecho, no se narran en la novela las famosas vistas entre el rey y el caballero. Si el Cantar junto con exaltar al Cid exaltaba al rey, es claro que esto último no estaba entre las intenciones de Huidobro.

Por su lado, el Romancero tiende a presentarnos a un Cid más contestatario, en posición de "vasallo arrogante", así por ejemplo en los romances "La Jura de Santa Gadea" (43-47), "Quejas de doña Jimena” (48-50) y "Cabalga Diego Laínez" (51-53), en todos los cuales se nos muestra a un Cid desafiante para con su rey. Huidobro, en cambio, aunque relata también estos pasajes (que el Cantar, en cambio, no nos cuenta) prefiere presentarnos en ellos a un Cid siempre mesurado y leal al rey, nunca desafiante de su autoridad: el buen vasallo por antonomasia. 
Sin embargo, no podríamos decir que Huidobro se pone en la misma posición enunciativa de los poetas medievales si solo se limitara a repetir más o menos en el mismo tono sus mecanismos de acercamiento al auditorio. Que la voz poética de Huidobro esté en la misma posición enunciativa que sus lectores implica la interiorización de sus propios mecanismos de acercamiento, para producir en su público (de una cultura distinta a la del público del juglar) una inmediatez semejante.

Una simple comparación de textos demostrará hasta qué punto el poeta logra involucrarnos en su Cid como lo hacían antaño los juglares.

El autor del Cantar suele utilizar imágenes a la vez expresivas y cotidianas para acercar sus palabras al público. Así, giros como "así s'partem unos d'otros commo la uña de la carne" (v. 375) para graficar el dolor de la separación del Cid y su familia; o interpelaciones tales como " $i$ sabor abriedes de ser e de comer en el palacio!" (v. 2208) para despertar en los oyentes el deseo de sentarse a la mesa del banquete; o los muy frecuentes afevos ("helos aquí") con los que pareciera que el juglar presenta en medio del corro de sus oyentes a los personajes mismos que evoca.

No está falta la Hazaña de giros similares con los que se evocan situaciones cotidianas a nosotros, de modo de situarnos con más facilidad dentro del relato. Citemos aquí solo uno particularmente expresivo.

Rodrigo ha dado muerte, para vengar el honor paterno, al conde Lozano, y acto seguido parte para la guerra tomando Montes Doca, al mismo tiempo que arriba a la corte del rey un enviado papal. Así nos presenta el cuadro Huidobro:

Mientras las bocas se entregan al placer nacional del comentario y de la discusión, Rodrigo con sus trescientos caballeros va a marchas forzadas sobre Montes Doca.

(Pensemos un momento que el ayer fuera hoy. ¡Muera el tiempo y el espacio! Nunca han vivido mucho. ¡Oh maravilloso Einstein! Viva la cuarta dimensión y los sesos físicos y metafísicos y con luces y con neblinas.

Los cafés de la Puerta del Sol están llenos de gente. En el café de Levante no cabe un alfiler, si no es de corbata y robado. Salen los periódicos de la tarde con grandes letras mayúsculas que se comen toda la vida alrededor, que se tragan los autos, las gentes, las casas y los tranvías. Solas en medio del Sahara, las grandes letras mayúsculas y los chicos gritando:

EL ASESINATO DEL CONDE LOZANO.

LA TOMA DE MONTES DOCA. 


\section{GRAVE AFFAIRE ENTRE EL REY Y EL PAPA (Mio Cid 84).}

Así es cómo Huidobro, echando mano a recursos que actualizan la antigua materia, nos hace revivir el ambiente que quiere que percibamos, como si los acontecimientos estuviesen pasando delante de nuestros ojos. No es otra cosa la que hubiese buscado también cualquier poeta oral.

\section{HUIDOBROY LAHAZAÑA. DEL JUGLARAL POETACREACIONISTA}

Aún quedaría hablar de cómo nuestro hecho comparatista, la posición enunciativa de la voz poética, "irradia" todo la novela. Ya la sola declaración, en la presentación de la obra, de que se trata no de una novela de novelista, sino de la novela de un poeta (Huidobro, Mio Cid 17) es una clave para entender cómo opera esta voz.

Considerar su obra como poesía antes que como novela, o más bien, definiéndose como poeta que escribe, en lugar de como novelista, da a la voz de Hazaña una actitud frente a lo que narra que la aproxima a la del poeta épico que cantaba las gestas de los héroes. En efecto, también los juglares que cantaron el Mio Cid podían considerarse, en primer lugar, poetas, pues sus obras fueron, sobre todo, poesía.

En los cantares, como ya se ha dicho, aunque exista un pretendido componente histórico, prima el arte sobre la narración, y la verdad poética sobre la verdad histórica (cfr. Montaner, "El Cantar" 271). El juglar que canta debe mantener el interés de su público sin perderse en sus propios versos ni en los vericuetos de la historia, que debe ser fácilmente recordable. Su objetivo es producir el gusto y, en el caso de las historias heroicas, mover a sus oyentes a la admiración por la vida portentosa del héroe cuyos hechos narra (cfr. De Chasca 16; Bowra 4, 91 y ss.). Esto lleva al poeta a echar mano de una idea ordenadora que le permita concatenar coherentemente la narración y que le permita también transmitir los sentimientos que conducen el relato, porque lo que importa, en el fondo, es ese sentimiento ordenador: los componentes afectivos no son ornamentales para el poeta oral, sino de la esencia misma de su poema (Montgomery 47). De Chasca puede así afirmar que "el juglar, como cualquier otro artista, obedecía a la necesidad de entrañar en la forma externa de su medio el significado total interno, y de organizar un sistema de acciones" (51), cuestión que se logra concretamente al orientar el relato bajo 
esa unidad del significado total interno, a la que Huidobro llamaría "verdad poética": los juglares no hablaban de los héroes, sino que presentaban al héroe en medio del corro (Rico 222).

La proximidad de la voz de Huidobro a la de los juglares, al tratarse siempre de poetas que narran historias, queda manifiesta al leer la "Nota de los Editores" que antecedió la primera edición de su obra y que se encuentra también publicada en la edición facsimilar que preparó Editorial Universitaria. En esa nota -que, de acuerdo a las notas bibliográficas de esa edición, bien podría haber sido escrita por el propio Huidobro (IX)- se afirma que el autor es el iniciador de un género, la hazaña, que sería "una especie de novela épica" cuyos episodios están "cantados [tómese nota del verbo utilizado] con absoluta libertad, tanta libertad que no han faltado quienes ingenuamente se extrañen de ciertos anacronismos voluntarios que el autor se complace en presentar en sus obras" (7). Luego, la nota de los editores continúa anunciando que el poeta está preparando otras hazañas de otros héroes, con las que piensa completar "el ciclo de los Paladines" (ibid.).

Podemos afirmar, entonces, que la posición enunciativa de la voz poética en Huidobro coincide con la de los juglares: cantar, poéticamente, las hazañas de un héroe, para producir admiración. Y aún más: dicha voz le impulsaba, al igual que a sus predecesores orales, a ensanchar su canto a ciclos épicos, a proponer no uno, sino varios héroes.

Se entiende, entonces, que Armando Uribe defienda el carácter poético de Hazaña, por sobre sus características de novela:

La novela, dice el Marqués de Sade, en su prólogo a les crimes del'Amour, debe ser verosímil. Basta que sea verosímil, si bien puede ser más —o menos. La poesía, en cambio, es verídica o no es. Su verdad está en sus palabras mismas.

Vicente Huidobro llama a esta hazaña suya del Cid, la novela de un poeta. Entre nosotros ¿quién se ha atrevido a tanto en prosa? (VII).

La poesía, entonces, proclama una verdad. La hace presente a través de sus palabras. A esto se refería Huidobro al declarar que solo le importaban la poesía y la verdad del poeta (Mio Cid 17): la verdad reveladora de las palabras, verdad que ensambla muy bien con sus postulados creacionistas, que pretenden concebir la realidad por la palabra misma.

Cuando el poeta oral representaba en medio de su público, su mismo oficio y técnica le daban ocasión para crear con sus palabras una realidad 
vivida por la comunidad de los oyentes: la inmediatez de la palabra hablada es inmersiva en grado sumo, el juglar actúa, vive su historia y siente al unísono con su audiencia.

Esa posición enunciativa del poeta oral no es en principio replicable para el poeta que trabaja por escrito. Sin embargo, el creacionismo permite a Huidobro retomar esa posición enunciativa, en medio de un contexto letrado, en el que el lector ya no está delante del poeta y las palabras quedan fijadas en el papel, concebidas ya no como un hecho que pasa, sino como una cosa externa que se ve. Siendo plenamente consciente de su arte-supraconsciente, por el delirio poético (Goic 88-89)- Huidobro da a sus textos un tratamiento que permite actualizarlos con cada lectura, jugando con el tiempo y el espacio de modo que invoque las imágenes que nos ofrece, haciéndolas presentes. Este juego es explícito y hace del narrador, de la voz, un personaje más de la Hazaña, que está siempre delante del lector para integrarlo, también a él, en la obra; como en el pasaje ya citado de la salida del Cid luego de la muerte del conde Lozano (Mio Cid 84). A través del texto leído, el Cid vuelve a vivir, es invocado: al modo de la rosa del poema huidobriano, que no ha de ser cantada, sino hecha florecer en el poema (cfr. Antología 17).

De ese modo, se consigue, por el medio escrito, al mismo tiempo la admiración actual por el héroe y la admiración por el arte del poeta que canta sus hazañas, pues el poeta ha estado siempre delante de nosotros.

Así, la recepción y tratamiento de la materia cidiana por parte de Huidobro -desde la posición poética de quien pretende evocar con sus palabras unos personajes y crear una relación con sus lectores, como hacían antaño los juglares- va más allá de lo que estos llegaron a hacer, pues consigue siempre dar un giro nuevo capaz de acercar los hechos al lector, pese a la distancia que supone, en principio, el obstáculo de la lectura, comparada con la inmediatez de la voz.

Esto, en primer lugar, porque en Huidobro, como nos señala Goic (5657) este mecanismo de acercamiento es plenamente consciente, cosa que no podemos afirmar para los poetas y juglares, pues para ellos esta era la única forma conocida de relatar una gesta. Aunque en algunos casos escribiesen sus textos, vivían en una cultura en la que el pensamiento escrito aún no estaba arraigado, lo que los llevaba a escribir pensando en la declamación oral de sus textos (Ong 97). Huidobro, en cambio, si utiliza técnicas para acercar el poema al público y darle vida a su relato, es fruto de una decisión buscada y deliberada. 
La razón de esta decisión está en su teoría poética. Al narrar desde esta posición, Huidobro se acerca a la realidad poética, la convoca, la crea. Entabla un diálogo con el lector, sí, pero también con la poesía misma, con los personajes, con la novela, la Gesta y el Cantar. Trata a sus fuentes como realidades autónomas, lo que termina por darles consistencia propia y existencia más allá de sí mismas. Esto es precisamente lo que busca el creacionismo: el intercambio entre el poeta, su propia novela, el Cantar y el Romancero, que finalmente aparecen como entes autónomos:

El texto se presenta ante nosotros no como la realización de un mensaje en un solo lenguaje cualquiera, sino como un complejo dispositivo que guarda variados códigos, capaz de transformar los mensajes recibidos y de generar nuevos mensajes, un generador informacional que posee rasgos de una persona con un intelecto altamente desarrollado. [...] En vez de la fórmula "el consumidor descifra el texto", es posible una más exacta: "el consumidor trata con el texto". Entra en contactos con él. El proceso de desciframiento del texto se complica extraordinariamente, pierde su carácter de acontecimiento finito que ocurre una vez, tornándose más parecido a los actos, que ya conocemos, de trato semiótico de un ser humano con otra persona autónoma (Lotman 20).

Así, tal y como las palabras cobraban fuerza para los oyentes cuando los juglares recitaban y evocaban a la existencia la gesta heroica, al acercarse el lector a la Hazaña y volver a leerla, actualiza todo el potencial creador de las palabras de Huidobro y la historia del Cid cobra vida de nuevo para él.

\section{BIBLIOGRAFÍA}

Anónimo. Cantar de Mio Cid. Edición, estudio y notas de Alberto Montaner, Barcelona, Real Academia de la Lengua Española, 2016.

Anónimo. Romancero. Edición de Paloma Díaz-Mas, Barcelona, Editorial Crítica, 1994.

Bowra, C. M. Heroic Poetry. Londres, Macmillan \& Co. Ltd, 1952.

Brunel, Pierre. "El hecho comparatista". Compendio de Literatura Comparada. Pierre

Brunel e Yves Chevrel (coord.), Ciudad de México, Siglo XXI Editores, 1994, pp. 21-50.

De Chasca, Edmund. El arte juglaresco en el cantar de Mio Cid. Barcelona, Gredos, 1967.

GENETtE, GÉRARD. "La Literatura a la segunda potencia”. Intertextualité. Edición y 
traducción de Desiderio Navarro, La Habana, Uneac/Casa de las Américas, pp. 53-62.

Goic, Cedomil. La poesía de Vicente Huidobro. Santiago, Ediciones Nueva Universidad, 1965.

Huidobro, Vicente. Antología poética. Selección y prólogo de Óscar Hahn, Santiago, Editorial Universitaria, 1997.

Mio Cid Campeador, Hazaña. Santiago, Editorial Andrés Bello, 1985.

Lotman, Iuri. "La semiótica de la cultura y el concepto de texto". Escritos: Revista del

Centro de Ciencias del Lenguaje 9, 1993, pp. 15-20.

Montaner, Alberto. "El Cantar de Mio Cid". Cantar de Mio Cid. Edición, estudio y

notas de Alberto Montaner, Barcelona, Real Academia de la Lengua Española, 2016, pp. 257-560.

"Presentación". Cantar de Mio Cid. Edición, estudio y notas de Alberto Montaner,

Barcelona, Real Academia de la Lengua Española, 2016, pp. IX-XII.

Montgomery, Thomas. "El Poema de Mio Cid: arte oral en transición”. Estudios sobre

épica medieval castellana. Leonardo Funes y Erica Janin (eds.), Buenos Aires, Oficina de

Publicaciones de Filosofìa y Letras Universidad de Buenos Aires, 2008, pp. 42-58.

Nivelle, Armand. “¿Para qué sirve la Literatura Comparada?” Teoría y praxis de la

Literatura Comparada. Manfred Schmeling (ed.), Barcelona/Caracas, Editorial Alfa, 1984, pp. 195-211.

"Nota de los Editores". Mio Cid Campeador, Hazaña. Vicente Huidobro, Edición

facsimilar de la primera publicada por la Compañía Iberoamericana de Publicaciones S. A.,

Madrid, 1929, Santiago, Editorial Universitaria, 2003, p. IX.

ONG, Walter. Oralidad y escritura, tecnologías de la palabra. Colombia, Fondo de Cultura Económica, 1999.

Rico, Francisco. "Un canto de frontera: 'La gesta de Mio Cid el de Bivar'”. Cantar de

Mio Cid. Edición, estudio y notas de Alberto Montaner, Barcelona, Real Academia de la Lengua Española, 2016, pp. 221-255.

Saldes Báez, Sergio. "Trayectoria en la Poética de Vicente Huidobro; acerca de tres de sus novelas". Cyber Humanitatis 14, 2000.

Subercaseaux, Bernardo. "La apropiación cultural en el pensamiento y la cultura de América Latina”. Estudios Públicos 30, 1988, pp. 125-135.

Uribe, Armando. "Prefacio". Mio Cid Campeador, Hazaña. Vicente Huidobro, Edición facsimilar de la primera edición publicada por la Compañía Iberoamericana de Publicaciones, S.A., Madrid, 1929, Santiago, Editorial Universitaria, 2003, pp. IV-VIII. 